\title{
Polymorphisms in the TLR3 gene are associated with risk for type 1 diabetes mellitus
}

\author{
Taís Silveira Assmann ${ }^{1,2}$, Letícia de Almeida Brondani ${ }^{1,2}$, Andrea Carla Bauer ${ }^{1}$, \\ Luis Henrique Canani ${ }^{2}$ and Daisy Crispim ${ }^{1,2}$ \\ ${ }^{1}$ Endocrine Division, Laboratory of Biology of Human Pancreatic Islet, Hospital de Clínicas de Porto Alegre, \\ Rua Ramiro Barcelos 2350, Prédio 12, $4^{\circ}$ Andar, CEP 90035-003 Porto Alegre, Rio Grande do Sul, Brazil and \\ ${ }^{2}$ Post-Graduate Program in Medical Sciences: Endocrinology, Universidade Federal do Rio Grande do Sul, \\ Porto Alegre, Rio Grande do Sul, Brazil
}

\author{
Correspondence \\ should be addressed \\ to D Crispim \\ Email \\ dcmoreira@hcpa.ufrgs.br
}

\begin{abstract}
Introduction: Viral pathogens seem to play a role in triggering the autoimmune destruction that leads to the development of type 1 diabetes mellitus (T1DM). Toll-like receptor 3 (TLR3) has been shown to recognize double-stranded RNA, a molecular signature of most viruses. It is expressed at high levels in pancreatic $\beta$-cells and immune cells, suggesting a role for it in the pathogenesis of T1DM. Therefore, the aim of this study was to investigate whether TLR3 polymorphisms are associated with T1DM.

Methods: Frequencies of the TLR3 rs11721827, rs13126816, rs5743313, rs7668666, and rs3775291 polymorphisms were analyzed in 449 T1DM patients and in 507 nondiabetic subjects. Haplotypes constructed from the combination of these polymorphisms were inferred using a Bayesian statistical method.

Results: The rs3775291 and rs13126816 polymorphisms were associated with T1DM, and the strongest association was observed for the additive model (odds ratio $(\mathrm{OR})=2.3,95 \% \mathrm{Cl} 1.3-4.2$ and $\mathrm{OR}=2.1,95 \% \mathrm{Cl} 1.3-3.1$ respectively). In the same way, the frequency of T1DM was higher as more risk alleles of the five polymorphisms were present $(P$-trend $=0.001)$. Moreover, in T1DM patients, the minor alleles of the rs5743313 and rs117221827 polymorphisms were associated with an early age at diagnosis and worse glycemic control.

Conclusion: The TLR3 rs3775291 and rs13126816 polymorphisms are associated with risk for T1DM, while the rs5743313 and rs11721827 polymorphisms are associated with age at T1DM diagnosis and poor glycemic control. The number of risk alleles of the five TLR3 polymorphisms in the haplotypes seems to influence the risk for T1DM, suggesting that these polymorphisms might interact in the susceptibility for the disease.

\section{Introduction}

Type 1 diabetes mellitus (T1DM) is characterized by severe autoimmune destruction of insulin-producing $\beta$-cells in the pancreas by $\mathrm{T}$ lymphocytes and macrophages infiltrating the islets of Langerhans $(1,2)$. Several epidemiological, experimental, and clinical studies indicate that environmental factors, such as viral pathogens, trigger the autoimmune destruction of $\beta$-cells in genetically susceptible subjects $(3,4,5,6)$.

The most well documented correlation between a virus and T1DM has been for enteroviruses, such as coxsackievirus $\mathrm{B}$ (CV-B), which exhibit specific tropism for the pancreas $(4,6,7,8)$. Serological and PCR analyses have shown that CV-B is expressed more frequently in T1DM patients than in healthy subjects (9). One CV-B4 strain was isolated from the pancreas of a deceased diabetic child, and this virus was able to induce diabetes when inoculated in a susceptible mouse strain (10). The pathogenic role of enteroviruses in T1DM seems to involve damage to $\beta$-cells and local induction of proinflammatory mediators (11).
(ㄷ) 2014 European Society of Endocrinology Printed in Great Britain
Published by Bioscientifica Ltd. 
The immune response to virus infection begins with the recognition of pathogen-associated molecular patterns (PAMPs) as 'nonself' signatures. This recognition occurs through host pattern recognition receptors (PRRs), and triggers intracellular signaling events that induce innate immunity. Many types of PRRs have been identified so far, including Toll-like receptors (TLRs), retinoic acidinducible gene 1 (RIG1)-like helicases (RLHs), and nucleotide-binding oligomerization domain (NOD)-like receptors (NLRs). These PRRs recognize specific PAMPs in different cellular compartments, inducing the expression of proinflammatory cytokines, chemokines, and co-stimulatory molecules, which eliminate the pathogens and active pathogen-specific adaptive immune responses $(12,13,14)$.

Of the PRRs, the most extensively studied are TLRs, which are type 1 transmembrane glycoproteins $(15,16)$. Human homologs are known to comprise at least 11 members with different response triggers (12). TLR3 has been shown to recognize double-stranded RNA (dsRNA), a molecular signature of most viruses, and it is expressed at high levels in human and mouse pancreatic $\beta$-cells and in antigen-presenting dendritic cells $(11,17)$, suggesting a potential role for this receptor in the infectious etiology of T1DM. However, to date, only one study evaluated the association between polymorphisms in the TLR3 gene and T1DM: Pirie et al. (18) reported that of nine TLR3 polymorphisms studied in a small sample of Zulu descent (South Africa), a significant association with risk for T1DM was found for the rs5743313 (C/T), rs5743315 (C/A), and $2690 \mathrm{~A} / \mathrm{G}$ (novel) polymorphisms. Nevertheless, correction of the $P$ values for the number of comparisons rendered the results no longer significant.

Thus, further studies are needed to investigate the association between TLR3 polymorphisms and T1DM in different populations. Within this context, the aim of this study was to investigate the association of the rs5743313 (C/T), rs3775291 (A/G), rs11721827 (A/C), rs13126816 (A/G), and rs7668666 (A/C) polymorphisms in the TLR3 gene with T1DM in a white population.

\section{Subjects and methods}

\section{Subjects, phenotype measurements, and laboratory analyses}

This was a case-control study designed to investigate whether the TLR3 rs5743313 (C/T), rs11721827 (A/C), rs3775291 (A/G), rs13126816 (A/G), and rs766866 (A/C) polymorphisms are associated with T1DM. The diabetic sample comprised 449 unrelated patients from the outpatient clinic at the Hospital de Clínicas de Porto Alegre (Rio Grande do Sul, Brazil). Patients were considered to have T1DM if they had been diagnosed with hyperglycemia according to ADA criteria before the age of 30 years, required insulin for glycemic control, and did not have a clinical profile compatible with other diabetes mellitus subtypes assessed by experienced endocrinologists (19). The nondiabetic group comprised 507 healthy blood donors who did not have diabetes mellitus or family history for this disease. All subjects were self-defined as white.

A standard questionnaire was used to collect information on gender, age, age at T1DM diagnosis, T1DM duration, and drug treatment. All patients underwent physical and laboratory evaluations. Serum and plasma samples were taken after $12 \mathrm{~h}$ of fasting for laboratory analyses. Plasma glucose levels were determined using the glucose oxidase method. HbA1c measurements were performed by different methods and results were traceable to the Diabetes Control and Complications Trial (DCCT) method by off-line calibration or through conversion formulae (20).

\section{Genotyping}

DNA was extracted from peripheral blood leukocytes by a standardized salting-out procedure (21). TLR3 polymorphisms were genotyped using primers and probes contained in the Human Custom TaqMan Genotyping Assay $20 \times$ (Life Technologies), and described in Table 1 . Reactions were conducted in 384-well plates, in a total $5 \mu$ reaction volume using 2 ng of genomic DNA, TaqMan Genotyping Master Mix $1 \times$ (Life Technologies), and Custom TaqMan Genotyping Assay $1 \times$. The plates were then positioned in a realtime PCR thermal cycler (ViiA7 Real-Time PCR System; Life Technologies) and heated for $10 \mathrm{~min}$ at $95^{\circ} \mathrm{C}$, followed by 50 cycles of $95^{\circ} \mathrm{C}$ for $15 \mathrm{~s}$ and $60^{\circ} \mathrm{C}$ for $1 \mathrm{~min}$. Fluorescence data files from each plate were analyzed using automated allele-calling software (Life Technologies).

The location of the rs11721827 (A/C), rs13126816 $(\mathrm{A} / \mathrm{G})$, rs5743313 (C/T), rs7668666 (A/C), and rs3775291 (A/G) polymorphisms at the TLR3 gene is shown in Fig. 1. TLR3 polymorphisms were selected from the International HapMap Project (22). Owing to linkage disequilibrium (LD) between some of the common polymorphisms in this gene, at least five polymorphisms had to be genotyped to estimate all haplotypes with more than 5\% frequency and that would cover $83 \%$ of all possible TLR3 haplotypes. The rs5743313 and rs3775291 polymorphisms were also 
Table 1 Primers and probes used for the genotyping of the analyzed $T L R 3$ polymorphisms.

\begin{tabular}{l} 
Polymorphisms \\
\hline rs117221827 (A/C) \\
rs13126816 (A/G) \\
rs5743313 (C/T) \\
rs7668666 (A/C) \\
rs3775291 (A/G)
\end{tabular}

\section{TaqMan MGB probes}

VIC: $5^{\prime}$-AAAACAATTACGAATGGACC-3'

FAM: 5'-ATAAAACAATTACTAATGGACC-3'

VIC: $5^{\prime}$-AACCTCCCATTTTGCTC-3'

FAM: $5^{\prime}$-ACCTCCCATCTTGCTC-3'

VIC: $5^{\prime}-\mathrm{TCTCCCGACCTCTCC-3^{ \prime }}$

FAM: $5^{\prime}$-TCTCCCAACCTCTCC-3'

VIC: $5^{\prime}$-TGTATTTTACACTAATTTTG-3'

FAM: $5^{\prime}$-TGTATTTTACACTCATTTTG- $3^{\prime}$

VIC: $5^{\prime}$-CCCTTACACATATTCAACC- $3^{\prime}$

FAM: $5^{\prime}$-CCTTACACATACTCAACC-3' selected on the basis of previous studies: Pirie et al. (18) reported that the rs5734313 polymorphism was associated with T1DM, while Ranjith-Kumar et al. (23) reported that the rs3775291 polymorphism was functional, being associated with natural resistance to HIV1 infection (24).

\section{Statistical analysis}

Allele frequencies were determined by gene counting, and departures from the Hardy-Weinberg equilibrium (HWE) were verified using $\chi^{2}$-tests. Allele and genotype frequencies were compared between groups of subjects using $\chi^{2}$-tests. Between all pairs of biallelic loci, we examined widely used measures of LD, Lewontin's $D^{\prime}\left|D^{\prime}\right|$ and $r^{2}$ (25). The haplotypes constructed from the combination of the five TLR3 polymorphisms and their frequencies were inferred using the Phase 2.1 program (Seattle, WA, USA), which implements a Bayesian statistical method (26). We also used this program to compare the distributions of different TLR3 haplotypes between T1DM patients and nondiabetic subjects through permutation analyses of 10000 random replicates (26).

Clinical and laboratory characteristics were compared between groups by using unpaired Student's $t$-test or $\chi^{2}$-test, as appropriate. Variables with normal distribution are presented as mean \pm s.D. Variables with skewed distribution were log-transformed before analyses and are presented as medians (minimum-maximum values). The magnitude of the association of different haplotypes with T1DM was estimated using odds ratio (OR) tests with 95\% CI, the results for which were considered statistically significant where $P \leq 0.05$. Bonferroni's correction was used to account for multiple comparisons. These statistical analyses were done using SPSS, version 18.0.

Power calculations (PEPI program, v. 4.0; Salt Lake City, UT, USA) showed that this study had a power of $\sim 80 \%$ at a significance level of 0.05 to detect an OR of 1.5 (for the presence of the mutated alleles).

\section{Results}

\section{Sample description}

The main clinical and laboratory characteristics of the 449 T1DM patients belonging to this study were as follows: mean age was $33.5 \pm 13.3$ years; age at T1DM diagnosis was 16 (1-30) years; mean HbA1c was $8.5 \pm 2.5 \%$ (69 \pm $12.0 \mathrm{mmol} / \mathrm{mol}$ ). Males comprised $49.8 \%$ of the sample. The mean age of the nondiabetic group was $44.0 \pm 7.8$ years, and males comprised $55.0 \%$ of the sample.

\section{Genotype and allele distributions}

Genotype and allele frequencies of the TLR3 rs11721827 (A/C), rs13126816 (A/G), rs5743313 (C/T), rs7668666 (A/C), and rs3775291 (A/G) polymorphisms in T1DM patients and nondiabetic subjects are depicted in Table 2 . All genotypes

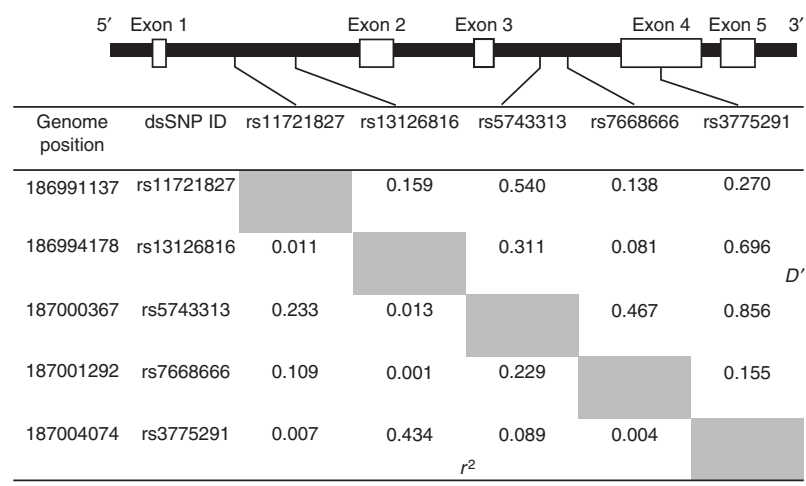

\section{Figure 1}

Genomic structure of TLR3 gene and pairwise linkage disequilibrium (LD) values for the five analyzed polymorphisms in this gene. In the upper part of the figure, the TLR3 gene structure and the positions of the analyzed polymorphisms are indicated. In the lower part, simple pairwise LD values, $\left|D^{\prime}\right|$ (right) and $r^{2}$ (left), are shown. 
Table 2 Genotype and allele frequencies of the TLR3 polymorphisms in patients with type 1 diabetes mellitus (T1DM) and nondiabetic subjects. Data are shown as $n(\%)$ or proportion.

\begin{tabular}{|c|c|c|c|}
\hline & $\begin{array}{c}\text { T1DM } \\
\text { patients }\end{array}$ & $\begin{array}{l}\text { Nondiabetic } \\
\text { subjects }\end{array}$ & $P$ value* \\
\hline rs11721827 (A/C) & $n=445$ & $n=493$ & \\
\hline \multicolumn{4}{|l|}{ Genotype } \\
\hline $\mathrm{A} / \mathrm{A}$ & 308 (69.2) & $338(68.6)$ & 0.053 \\
\hline $\mathrm{A} / \mathrm{C}$ & $115(25.8)$ & $144(29.2)$ & \\
\hline $\mathrm{C} / \mathrm{C}$ & $22(5.0)$ & $11(2.2)$ & \\
\hline \multicolumn{4}{|l|}{ Allele } \\
\hline A & 0.82 & 0.83 & 0.598 \\
\hline $\mathrm{C}$ & 0.18 & 0.17 & \\
\hline rs13126816 (A/G) & $n=432$ & $n=422$ & \\
\hline \multicolumn{4}{|l|}{ Genotype } \\
\hline A/A & $45(10.4)$ & $71(16.8)$ & $1 \times 10^{-3}$ \\
\hline A/G & $167(38.7)$ & $182(43.1)$ & \\
\hline $\mathrm{G} / \mathrm{G}$ & $220(50.9)$ & $169(40.1)$ & \\
\hline \multicolumn{4}{|l|}{ Allele } \\
\hline A & 0.30 & 0.38 & $1 \times 10^{-4}$ \\
\hline G & 0.70 & 0.62 & \\
\hline rs5743313 (C/T) & $n=449$ & $n=507$ & \\
\hline \multicolumn{4}{|l|}{ Genotype } \\
\hline $\mathrm{C} / \mathrm{C}$ & $273(60.8)$ & $322(63.5)$ & 0.561 \\
\hline $\mathrm{C} / \mathrm{T}$ & $147(32.7)$ & 159 (31.4) & \\
\hline $\mathrm{T} / \mathrm{T}$ & $29(6.5)$ & $26(5.1)$ & \\
\hline \multicolumn{4}{|l|}{ Allele } \\
\hline C & 0.77 & 0.79 & 0.311 \\
\hline $\mathrm{T}$ & 0.23 & 0.21 & \\
\hline rs7668666 (A/C) & $n=434$ & $n=423$ & \\
\hline \multicolumn{4}{|l|}{ Genotype } \\
\hline $\mathrm{A} / \mathrm{A}$ & $32(7.4)$ & 46 (10.9) & 0.063 \\
\hline $\mathrm{A} / \mathrm{C}$ & $151(34.8)$ & $162(38.3)$ & \\
\hline $\mathrm{C} / \mathrm{C}$ & $251(57.8)$ & $215(50.8)$ & \\
\hline \multicolumn{4}{|l|}{ Allele } \\
\hline A & 0.25 & 0.30 & 0.017 \\
\hline $\mathrm{C}$ & 0.75 & 0.70 & \\
\hline rs3775291 (A/G) & $n=448$ & $n=461$ & \\
\hline \multicolumn{4}{|l|}{ Genotype } \\
\hline A/A & $22(4.9)$ & $69(15.0)$ & $1 \times 10^{-3}$ \\
\hline $\mathrm{A} / \mathrm{G}$ & $198(44.2)$ & $202(43.8)$ & \\
\hline $\mathrm{G} / \mathrm{G}$ & $228(50.9)$ & $190(41.2)$ & \\
\hline \multicolumn{4}{|l|}{ Allele } \\
\hline A & 0.27 & 0.37 & $1 \times 10^{-6}$ \\
\hline G & 0.73 & 0.67 & \\
\hline
\end{tabular}

* $P$ values were computed by $\chi^{2}$-test comparing T1DM patients and nondiabetic subjects. Only $P$ values lower than the Bonferroni's threshold $(P=0.010)$ were considered statistically significant.

were in agreement with those predicted by the HWE in nondiabetic subjects $(P>0.05)$. Distributions of the rs5743313, rs11721827, and rs7668666 polymorphisms did not differ statistically between the two analyzed samples after Bonferroni's correction. Moreover, frequencies of these three polymorphisms also did not differ statistically when assuming dominant, recessive, or additive inheritance models for the presence of the mutated alleles after Bonferroni's correction (data not shown).
Both genotype and allele frequencies of the rs3775291 polymorphism were differently distributed between T1DM patients and nondiabetic subjects $\left(P=1 \times 10^{-3}\right.$ and $P=1 \times$ $10^{-6}$ respectively) after Bonferroni corrections (Table 2 ). The rs3775291G allele was also associated with risk for T1DM under additive and dominant inheritance models ( $P=0.004$ and $P=0.005$ respectively), and the association was stronger for the additive model $(\mathrm{OR}=2.3,95 \%$ CI 1.3-4.2). Genotype and allele frequencies of the rs13126816 polymorphism differed significantly between T1DM patients and nondiabetic subjects $\left(P=1 \times 10^{-3}\right.$ and $P=1 \times 10^{-4}$ respectively) after Bonferroni corrections (Table 2). Furthermore, the rs13126816G allele was associated with risk for T1DM under dominant, recessive, and additive models $\left(P=0.006, P=1 \times 10^{-3}\right.$, and $P=1 \times 10^{-4}$ respectively), with the strongest association being observed for the additive model $(\mathrm{OR}=2.1,95 \%$ CI 1.3-3.1).

Table 3 illustrates the clinical and laboratory characteristics of T1DM patients grouped according to the presence of the risk allele (mutated) of each one of the analyzed TLR3 polymorphisms. Gender, age, age at T1DM diagnosis, fasting plasma glucose (FPG), and HbA1c did not differ between groups of patients broken down by the presence of the mutated alleles of the rs3775291, rs13126816, and rs7668666 polymorphisms, taking into account Bonferroni corrections. On the other hand, patients carrying the $\mathrm{T}$ allele of the rs5743313 polymorphism are younger and had an early age at T1DM diagnosis and a worse glycemic control as compared with patients with the $\mathrm{C} / \mathrm{C}$ genotype (Table 3 ). In addition, patients carrying the rs117221827C allele showed an early age at diagnosis and higher levels of FPG than patients with the A/A genotype.

\section{Haplotype distributions and LD}

We used a Bayesian statistical method to estimate the frequency of different haplotypes produced by the combination of the five TLR3 polymorphisms in T1DM patients and nondiabetic subjects. Thirty-two haplotypes were inferred in both samples, but only those haplotypes with frequencies higher than 1\% are shown in Table 4. Permutation analysis showed that the distributions of all inferred haplotypes were statistically different between T1DM patients and nondiabetic subjects $(P=0.001)$ because of differences in the frequencies of $\mathrm{Ht} 1, \mathrm{Ht} 2$, Ht10, Ht12, and Ht16. While Ht10, Ht12, and Ht16 were more frequent in T1DM patients, $\mathrm{Ht} 1$ and $\mathrm{Ht} 2$ showed the opposite result, being more frequent in nondiabetic subjects (Table 4). It is noteworthy that taking into 
Table 3 Clinical and laboratory characteristics of T1DM patients broken down by the presence of the mutated alleles of the analyzed TLR3 polymorphisms.

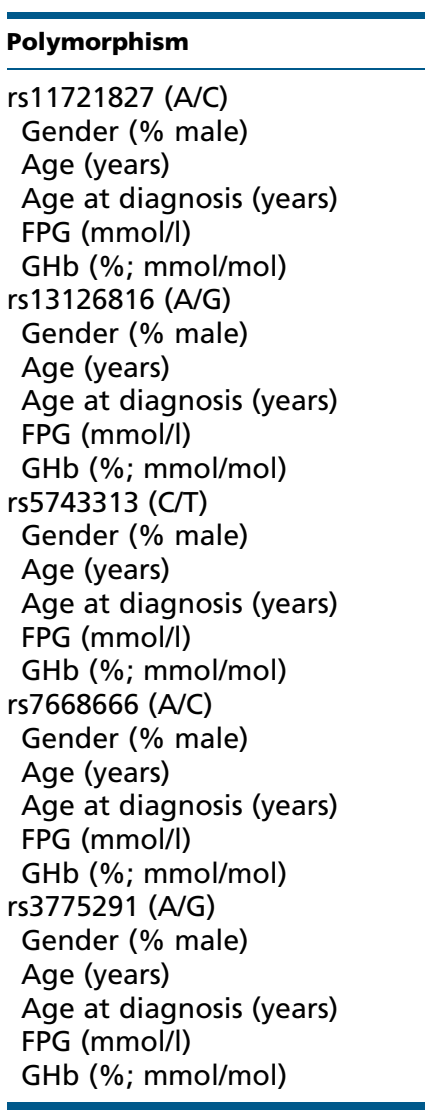

\begin{tabular}{c}
\hline Other genotype \\
\hline $\mathrm{A} / \mathrm{A}$ \\
57.6 \\
$38.7 \pm 11.2$ \\
$16(1-30)$ \\
$6.1(2.3-33.5)$ \\
$8.4 \pm 2.1 ; 68.0 \pm 11.0$ \\
$\mathrm{~A} / \mathrm{A}$ \\
47.5 \\
$39.6 \pm 10.2$ \\
$15(2-25)$ \\
$7.4(2.2-23.4)$ \\
$9.1 \pm 2.5 ; 76.0 \pm 13.0$ \\
$\mathrm{C} / \mathrm{C}$ \\
53.5 \\
$40.3 \pm 10.3$ \\
$17(2-30)$ \\
$6.2(2.1-19.1)$ \\
$8.1 \pm 1.8 ; 65.0 \pm 9.0$ \\
$\mathrm{~A} / \mathrm{A}$ \\
59.2 \\
$37.6 \pm 12.5$ \\
$13(2-26)$ \\
$8.2(3.6-17.9)$ \\
$7.8 \pm 1.5 ; 62.0 \pm 8.0$ \\
$\mathrm{~A} / \mathrm{A}$ \\
46.3 \\
$39.2 \pm 12.4$ \\
$14(1-30)$ \\
$9.5(3.6-19.3)$ \\
$8.6 \pm 2.0 ; 70.0 \pm 10.0$ \\
\end{tabular}

\begin{tabular}{c}
\hline Presence of risk allele \\
$\mathrm{A} / \mathrm{C}+\mathrm{C} / \mathrm{C}$ \\
55.0 \\
$38.2 \pm 13.8$ \\
$10(1-26)$ \\
$12.1(2.1-26.5)$ \\
$9.1 \pm 1.9 ; 76.0 \pm 10.0$ \\
$\mathrm{~A} / \mathrm{G}+\mathrm{G} / \mathrm{G}$ \\
58.4 \\
$38.6 \pm 12.4$ \\
$14(1-30)$ \\
$10.2(2.1-33.5)$ \\
$8.4 \pm 1.8 ; 68.0 \pm 9.0$ \\
$\mathrm{C} / \mathrm{T}+\mathrm{T} / \mathrm{T}$ \\
58.5 \\
$36.8 \pm 13.8$ \\
$10(1-29)$ \\
$12.1(2.1-33.5)$ \\
$9.2 \pm 2.1 ; 77.0 \pm 11.0$ \\
$\mathrm{~A} / \mathrm{C}+\mathrm{C} / \mathrm{C}$ \\
55.6 \\
$38.2 \pm 12.3$ \\
$14(1-30)$ \\
$8.6(2.1-33.5)$ \\
$8.6 \pm 2.0 ; 70.0 \pm 10.0$ \\
$\mathrm{~A} / \mathrm{G}+\mathrm{G} / \mathrm{G}$ \\
57.2 \\
$38.7 \pm 12.2$ \\
$8(2-22)$ \\
$8.6(2.1-33.5)$ \\
$8.6 \pm 1.9 ; 70.0 \pm 10.0$ \\
\end{tabular}

\begin{tabular}{c}
\hline P value* \\
\hline 0.81 \\
0.650 \\
$1 \times 10^{-4}$ \\
$1 \times 10^{-4}$ \\
0.013
\end{tabular}

FPG, fasting plasma glucose; GHb, glycated hemoglobin. * $P$ values were obtained from Student's $t$-test or $\chi^{2}$-test. Only $P$ values lower than the Bonferroni's threshold $(0.010)$ were considered statistically significant.

account both $\left|D^{\prime}\right|$ and $r^{2}$ measurements, we did not find any significant LD between all pairs of combination of the five analyzed polymorphisms (Fig. 1).

Figure 2 depicts T1DM patients and nondiabetic subjects broken down according to the presence of the number of risk alleles (mutated) in the estimated haplotypes: i) 0-2; ii) 3-4; iii) 5-7, and iv) 8-10 risk alleles. Interestingly, the prevalence of T1DM is higher as more risk alleles are present in the patients $(P$-trend $=0.001)$. Moreover, T1DM patients carrying haplotypes with more than five risk alleles of the analyzed polymorphisms had higher levels of FPG than patients with $\leq 5$ risk alleles (183.0 (36-603) vs 130.0 (36-420) $\mathrm{mg} / \mathrm{dl}$ respectively; $P=1 \times 10^{-4}$ ). Age at T1DM diagnosis, gender, and HbA1c did not differ between these groups after Bonferroni corrections (data not shown).

\section{Discussion}

The ligation of dsRNA to the TLR3 leads to receptor dimerization and to the resultant recruitment of the adaptor molecule, TRIF (TIR-domain-containing adaptor inducing IFN- $\beta$ ), to the cytoplasmic domain of TLR3, known as TIR (Toll-IL1R-resistance). TRIF initiates signaling pathways that activate the downstream transcription factors interferon regulatory factor 3 (IRF3) and IRF7 and nuclear factor $\mathrm{\kappa B}$, which in turn trigger the expression and secretion of type 1 interferons (IFN1), inflammatory cytokines, and chemokines, as well as the maturation of dendritic cells, a key event in the generation of adaptive immunity $(14,27,28)$. This local inflammation coupled with triggering of antiviral defenses will in most cases eradicate the viral infection. However, in some genetically susceptible subjects, these cellular attempts to eradicate the infection might go wrong and induce progressive inflammation and prolonged pancreatic $\beta$-cell death, thus predisposing for T1DM development (11). Accordingly, IFN1 production has been implicated as a potential mediator of viral/dsRNA-induced T1DM $(29,30,31)$.

Viral infections or dsRNA increase the expression of mRNAs encoding for TLR3 and for genes downstream of its 
Table 4 Haplotypes of the TLR3 gene in T1DM patients and nondiabetic subjects. Data are presented as proportion.

\begin{tabular}{|c|c|c|c|}
\hline Haplotypes & $\begin{array}{c}\text { T1DM } \\
\text { patients* } \\
(n=898)\end{array}$ & $\begin{array}{c}\text { Nondiabetic } \\
\text { subjects* } \\
(n=844)\end{array}$ & $\begin{array}{c}\text { Frequency in } \\
\text { the total } \\
\text { sample }\end{array}$ \\
\hline $\mathrm{Ht} 1(\mathrm{~A} A \subset A A)^{\dagger}$ & 0.016 & 0.035 & 0.025 \\
\hline $\mathrm{Ht} 2(\mathrm{~A} A \subset A \mathrm{~A})^{\dagger}$ & 0.008 & 0.026 & 0.016 \\
\hline $\mathrm{Ht3}(\mathrm{A} A \mathrm{~A} C \mathrm{C})$ & 0.129 & 0.125 & 0.127 \\
\hline $\mathrm{Ht} 4$ (A A C C G) & 0.072 & 0.102 & 0.086 \\
\hline $\mathrm{Ht8}$ (A A T C G) & 0.023 & 0.025 & 0.024 \\
\hline $\mathrm{Ht9}(\mathrm{A} G \mathrm{C}$ A A) & 0.019 & 0.034 & 0.026 \\
\hline $\mathrm{Ht} 10(\mathrm{~A} G C \mathrm{~A} G)^{\dagger}$ & 0.191 & 0.124 & 0.157 \\
\hline $\mathrm{Ht} 11$ (A G C C A) & 0.051 & 0.050 & 0.051 \\
\hline $\mathrm{Ht} 12\left(\mathrm{~A} \mathrm{G} \mathrm{C} \mathrm{C} \mathrm{G)}{ }^{\dagger}\right.$ & 0.249 & 0.206 & 0.229 \\
\hline Ht14 (A G T A G) & 0.020 & 0.012 & 0.016 \\
\hline $\mathrm{Ht} 16\left(\mathrm{~A} \mathrm{G} \mathrm{T} \mathrm{C} \mathrm{G)}{ }^{\dagger}\right.$ & 0.080 & 0.058 & 0.069 \\
\hline $\mathrm{Ht} 19$ (C A C C A) & 0.012 & 0.011 & 0.012 \\
\hline $\mathrm{Ht} 24$ (C A T C G) & 0.010 & 0.014 & 0.012 \\
\hline $\mathrm{Ht} 26$ (C G C A G) & 0.014 & 0.010 & 0.012 \\
\hline Ht28 (C G C C G) & 0.039 & 0.028 & 0.034 \\
\hline Ht29 (C G T A A) & 0.005 & 0.011 & 0.007 \\
\hline Ht30 (C G T A G) & 0.017 & 0.013 & 0.015 \\
\hline Ht32 (C G T C G) & 0.037 & 0.025 & 0.031 \\
\hline
\end{tabular}

$n$, number of chromosomes. The first letter of the haplotypes refers to the rs11721827 polymorphism, the second to the rs 13126816 polymorphism, the third to the rs5743313 polymorphism, the forth to the rs7668666 polymorphism, and the fifth to the rs3775291 polymorphism. Permutation ${ }^{*} P$ value $=0.001$ for comparisons of haplotype frequencies between groups. ${ }^{\dagger}$ Adjusted residuals which deviated from expected values $(P$ values $<0.05)$

signaling pathway in rat and human $\beta$-cells $(32,33,34,35)$. Therefore, triggering of TLR3 by a synthetic analog of viral dsRNA, poly(I:C), precipitates the development of diabetes in animal models $(30,31,36,37,38)$. Infection of $\mathrm{Tlr}^{-1-}$ mice caused diabetes due to impaired IFN1 responses and virus-induced $\beta$-cell damage rather than $\mathrm{T}$ cell-mediated autoimmunity, suggesting that optimal functioning of viral sensors and prompt IFN1 responses are required to prevent diabetes when caused by a virus that infects and damages $\beta$-cells (39).

Interestingly, Alkanani et al. (40) reported that activating peripheral blood mononuclear cells (PBMNCs) with TLR3, TLR4, or TLR7/8 agonists in vitro led to dysregulated IL1 $\beta$ and IL6 pathways in the monocytes and myeloid dendritic cells from islet autoantibodies-positive subjects vs seronegative individuals. This dysregulation was more pronounced in children aged $<11$ years, implying that alterations in the innate immune system are detectable in genetically susceptible individuals and could be linked with the early course of T1DM. Eleftherohorinou et al. (41) developed a novel pathwaybased method to assess the combined effect of more than 20000 single nucleotide polymorphisms (SNPs) acting within 84 pathways associated with innate and acquired immune responses to pathogens, and applied it to data from 14000 subjects from the UK, with seven common diseases including T1DM. They showed that multiple inflammatory pathways, containing 205 SNPs, were associated with T1DM. These SNPs, including SNPs in genes activated by TLR3, were found to be highly predictive of T1DM. However, until now, no genomewide scan study showed an association between the $4 \mathrm{q} 35$ region, where is located the TLR3 gene, and T1DM. The TLR3-closest signal associated with T1DM was the $4 \mathrm{q} 27$ region, which contains the IL2 gene $(42,43,44)$.

Within this context, TLR3 is a plausible candidate gene for T1DM susceptibility. Thus, here, we analyzed the association of five TLR3 polymorphisms with T1DM. Frequencies of the TLR3 rs5743313, rs11721827, and rs7668666 polymorphisms were not significantly different between T1DM patients and nondiabetic subjects; however, the rs13126816 and rs3775291 polymorphisms were significantly associated with risk for T1DM, probably under an additive inheritance model. Interestingly, the prevalence of T1DM was higher as more risk alleles of the five analyzed polymorphisms were present in the TLR3 haplotypes.

As already mentioned, in addition to this study, only the study of Pirie et al. (18) evaluated the association between TLR3 polymorphisms and T1DM. These authors reported that the major allele in the rs5743313

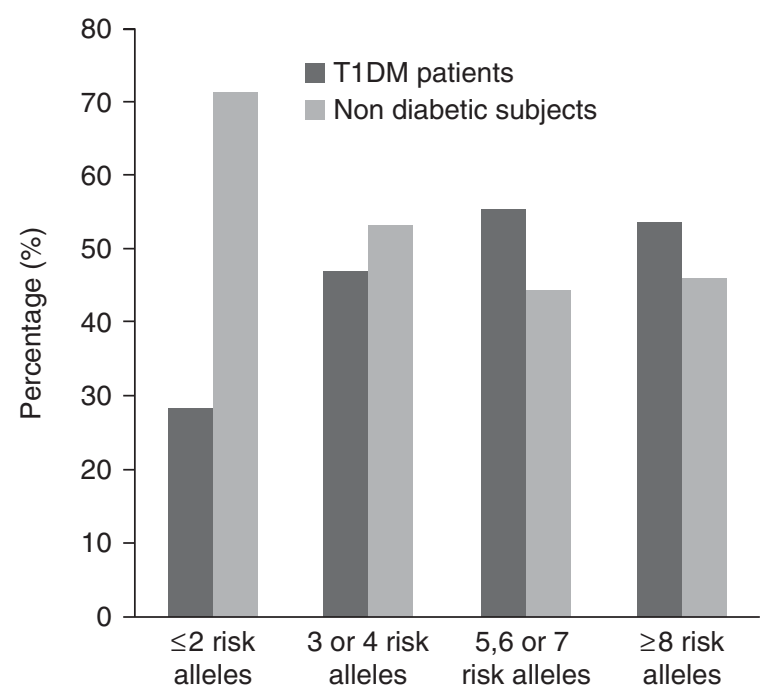

\section{Figure 2}

T1DM patients and nondiabetic subjects broken down by the number of risk alleles of the analyzed polymorphisms in the estimated TLR3 haplotypes. Data are presented as percentage. $P$ value was obtained using $\chi^{2}$-test. $P$-trend $=0.001$. 
polymorphism and the minor alleles in the rs 5743315 and $2690 \mathrm{~A} / \mathrm{G}$ polymorphisms were associated with risk for T1DM; nevertheless, probably due to the small sample size analyzed, this association was not maintained after correction for multiple comparisons. We were not able to evaluate the rs5743315 (C/A) polymorphism in our population because only the $\mathrm{C}$ allele is found in Europeans (http://www.ncbi.nlm.nih.gov/projects/SNP/snp_ref. cgi?rs =5743315). The novel polymorphism $(2690 \mathrm{~A} / \mathrm{G})$ described by Pirie et al. (18) is in complete LD with the rs5743315 polymorphism and, as a result, its minor allele will also probably not be found in Europeans. The rs5743313 polymorphism was analyzed in both studies: our data indicated no association between this polymorphism and T1DM, while the results of Pirie et al. (18) suggested a weak association with T1DM. These contradictory results may be explained by ethnic differences between the two populations because distributions of the TLR3 polymorphisms are clearly different between African and European or Caucasian populations.

In this study, for the first time, we reported an association of the TLR3 rs5743313 and rs117221827 polymorphisms with age at T1DM diagnosis and glycemic control in T1DM patients. The rs3775291 polymorphism was only marginally associated with age at T1DM diagnosis. Furthermore, T1DM patients carrying TLR3 haplotypes with more than five risk alleles of the analyzed polymorphisms had significantly higher levels of FPG than patients with $\leq 4$ risk alleles. Further studies are needed to confirm this data and also to clarify how these polymorphisms influence age at T1DM diagnosis and glycemic control.

The exact mechanisms by which TLR3 polymorphisms contribute to T1DM pathogenesis remain yet to be explored. The rs5743313, rs11721827, rs13126816, and rs7668666 polymorphisms are intronic, and probably are not real disease-causing variants, but could be simply reflecting the effects of a functional variant located elsewhere in the TLR3 gene. However, as it is known that some introns may contain regulatory sequences or even encode RNAs with regulatory functions or a protein; we cannot exclude a functional effect of these polymorphisms. The rs3775291 polymorphism in exon 4 results in amino acid substitution (Leu412Phe), affecting a residue in the hydrophobic core of the TLR3 extracellular domain (ectodomain - ECD) that is absolutely conserved in all species from mammals to fish (23). The TLR3 ECD has a horseshoe-like shape, characteristic of multiple leucinerich repeats (LRR), that possibly increases the available surface for dsRNA binding in this region (45). RanjithKumar et al. (23) reported that the 412Phe (G) allele causes a 30\% loss of activity of the TLR3 in response to its ligands, presumably by destabilizing the LRR architecture. Moreover, another in vitro study showed that TLR3 molecules carrying the 412Phe allele allow increased CV-B replication compared with Leu412 receptors (46). However, Sironi et al. (24) reported that PBMNCs from individuals carrying the 412Phe allele sustained lower HIV1 replication compared with that of Leu/Leu homozygotes. Although further studies are necessary to evaluate the effect of the rs3775291 (Leu412Phe) in the activity of TLR3 in pancreatic $\beta$-cells, we hypothesized that during infection with a $\beta$-cell tropic virus, the attenuated activity of the TLR3 412Phe mutant in hematopoietic cells may lead to blunted IFN1 response, uncontrolled virus replication and, consequently, T1DM. This hypothesis is in agreement with the results of McCartney et al. (39), showing that infection in $T l r 3^{-/-}$ mice caused diabetes due to impaired IFN1 responses and virus-induced $\beta$-cell damage.

Some factors could have interfered with the findings of this study. First, we cannot rule out the possibility of population stratification bias when analyzing our samples, even though only white subjects were studied and both T1DM patients and nondiabetic subjects were recruited from the same hospital, thus reducing the risk of falsepositive/negative associations due to this bias. Second, we cannot fully exclude the possibility of a type II error when analyzing the association between the analyzed polymorphisms and T1DM. Even though our power to detect an OR of 1.5 was $\sim 80 \%$ for all analyzed polymorphisms, we cannot fully exclude the possibility that the TLR3 rs5743313, rs11721827, and rs7668666 polymorphisms would be associated with T1DM with lower ORs. Additional genetic studies are needed in order to confirm the association of TLR3 polymorphisms with risk for T1DM in different ethnicities.

In conclusion, the results of this study indicate that the TLR3 rs3775291 and rs13126816 polymorphisms are associated with risk for T1DM in white Brazilian subjects. Moreover, the prevalence of this disease increases as more risk alleles of the five analyzed polymorphisms are present in the TLR3 haplotypes, indicating that they might interact in the susceptibility for T1DM. The TLR3 rs11721827 and rs5743313 polymorphisms seem to be associated with an early age at T1DM diagnosis and a worse glycemic control in our population.

Declaration of interest

The authors declare that there is no conflict of interest that could be perceived as prejudicing the impartiality of the research reported. 


\section{Funding}

This study was supported by grants from the Conselho Nacional de Desenvolvimento Científico e Tecnólogico (CNPq), Fundação de Amparo à Pesquisa do Estado do Rio Grande do Sul (FAPERGS), Coordenação de Aperfeiçoamento de Pessoal de Nível Superior (CAPES), and Fundo de Incentivo à Pesquisa e Eventos (FIPE) at Hospital de Clínicas de Porto Alegre. D Crispim and L H Canani are recipients of scholarships from CNPq.

\section{References}

1 Gillespie KM. Type 1 diabetes: pathogenesis and prevention. CMAJ: Canadian Medical Association Journal 2006175 165-170. (doi:10.1503/cmaj.060244)

2 van Belle TL, Coppieters KT \& von Herrath MG. Type 1 diabetes: etiology, immunology, and therapeutic strategies. Physiological Reviews 201191 79-118. (doi:10.1152/physrev.00003.2010)

3 Maahs DM, West NA, Lawrence JM \& Mayer-Davis EJ. Epidemiology of type 1 diabetes. Endocrinology and Metabolism Clinics of North America 201039 481-497. (doi:10.1016/j.ecl.2010.05.011)

4 Coppieters KT, Boettler T \& von Herrath M. Virus infections in type 1 diabetes. Cold Spring Harbor Perspectives in Medicine 20122 a007682. (doi:10.1101/cshperspect.a007682)

5 Knip M, Veijola R, Virtanen SM, Hyöty H, Vaarala O \& Akerblom HK. Environmental triggers and determinants of type 1 diabetes. Diabetes 200554 (Suppl 2) S125-S136. (doi:10.2337/diabetes.54.suppl_2.S125)

6 Jaidane $\mathrm{H} \&$ Hober D. Role of coxsackievirus B4 in the pathogenesis of type 1 diabetes. Diabetes \& Metabolism 200834 537-548. (doi:10.1016/ j.diabet.2008.05.008)

7 Filippi CM \& von Herrath MG. Viral trigger for type 1 diabetes: pros and cons. Diabetes 200857 2863-2871. (doi:10.2337/db07-1023)

8 Tauriainen S, Oikarinen S, Oikarinen M \& Hyoty H. Enteroviruses in the pathogenesis of type 1 diabetes. Seminars in Immunopathology 201133 45-55. (doi:10.1007/s00281-010-0207-y)

9 Zipris D. Epidemiology of type 1 diabetes and what animal models teach us about the role of viruses in disease mechanisms. Clinical Immunology 2009131 11-23. (doi:10.1016/j.clim.2008.12.011)

10 Yoon JW, Austin M, Onodera T \& Notkins AL. Isolation of a virus from the pancreas of a child with diabetic ketoacidosis. New England Journal of Medicine 1979300 1173-1179. (doi:10.1056/ NEJM197905243002102)

11 Eizirik DL, Colli ML \& Ortis F. The role of inflammation in insulitis and $\beta$-cell loss in type 1 diabetes. Nature Reviews. Endocrinology 20095 219-226. (doi:10.1038/nrendo.2009.21)

12 Kumar H, Kawai T \& Akira S. Pathogen recognition in the innate immune response. Biochemical Journal 2009420 1-16. (doi:10.1042/BJ20090272)

13 Wilkins C \& Gale M Jr. Recognition of viruses by cytoplasmic sensors. Current Opinion in Immunology 201022 41-47. (doi:10.1016/j.coi.2009. 12.003)

14 Takeuchi O \& Akira S. Pattern recognition receptors and inflammation. Cell 2010140 805-820. (doi:10.1016/j.cell.2010.01.022)

15 Meylan E, Tschopp J \& Karin M. Intracellular pattern recognition receptors in the host response. Nature 2006442 39-44. (doi:10.1038/ nature04946)

16 Arancibia SA, Beltran CJ, Aguirre IM, Silva P, Peralta AL, Malinarich F \& Hermoso MA. Toll-like receptors are key participants in innate immune responses. Biological Research 2007 40 97-112. (doi:10.4067/S071697602007000200001)

17 Alexopoulou L, Holt AC, Medzhitov R \& Flavell RA. Recognition of double-stranded RNA and activation of NF- $\mathrm{BB}$ by Toll-like receptor 3 . Nature 2001413 732-738. (doi:10.1038/35099560)

18 Pirie FJ, Pegoraro R, Motala AA, Rauff S, Rom L, Govender T \& Esterhuizen TM. Toll-like receptor 3 gene polymorphisms in South African Blacks with type 1 diabetes. Tissue Antigens 200566 125-130. (doi:10.1111/j.1399-0039.2005.00454.x)
19 American Diabetic Association. Diagnosis and classification of diabetes mellitus. Diabetes Care 201336 (Suppl 1) S67-S74. (doi:10.2337/dc13S067)

20 Camargo JL, Zelmanovitz T, Paggi A, Friedman R \& Gross JL. Accuracy of conversion formulae for estimation of glycohaemoglobin. Scandinavian Journal of Clinical and Laboratory Investigation $1998 \mathbf{5 8}$ 521-528. (doi:10.1080/00365519850186337)

21 Lahiri DK \& Nurnberger JI. A rapid non-enzymatic method for the preparation of HMW DNA from blood for RFLP studies. Nucleic Acids Research 199119 5444. (doi:10.1093/nar/19.19.5444)

22 International HapMap Consortium. The International HapMap Project. Nature 2003426 789-796. (doi:10.1038/nature02168)

23 Ranjith-Kumar CT, Miller W, Sun J, Xiong J, Santos J, Yarbrough I, Lamb RJ, Mills J, Duffy KE, Hoose $S$ et al. Effects of single nucleotide polymorphisms on Toll-like receptor 3 activity and expression in cultured cells. Journal of Biological Chemistry 2007282 17696-17705. (doi:10.1074/jbc.M700209200)

24 Sironi M, Biasin M, Cagliani R, Forni D, De Luca M, Saulle I, Lo Caputo S, Mazzotta F, Macias J, Pineda JA et al. A common polymorphism in TLR3 confers natural resistance to HIV-1 infection. Journal of Immunology $2012 \mathbf{1 8 8}$ 818-823. (doi:10.4049/jimmunol. 1102179)

25 Hedrick PW. Gametic disequilibrium measures: proceed with caution. Genetics 1987117 331-341.

26 Stephens M, Smith NJ \& Donnelly P. A new statistical method for haplotype reconstruction from population data. American Journal of Human Genetics 200168 978-989. (doi:10.1086/319501)

27 Kawai T \& Akira S. TLR signaling. Cell Death and Differentiation 200613 816-825. (doi:10.1038/sj.cdd.4401850)

28 Botos I, Liu L, Wang Y, Segal DM \& Davies DR. The Toll-like receptor 3:dsRNA signaling complex. Biochimica et Biophysica Acta 20091789 667-674. (doi:10.1016/j.bbagrm.2009.06.005)

29 Huang X, Yuang J, Goddard A, Foulis A, James RF, Lernmark A, PujolBorrell R, Rabinovitch A, Somoza N \& Stewart TA. Interferon expression in the pancreases of patients with type I diabetes. Diabetes $1995 \mathbf{4 4}$ 658-664. (doi:10.2337/diab.44.6.658)

30 Devendra D, Jasinski J, Melanitou E, Nakayama M, Li M, Hensley B, Paronen J, Moriyama H, Miao D, Eisenbarth GS et al. Interferon- $\alpha$ as a mediator of polyinosinic:polycytidylic acid-induced type 1 diabetes. Diabetes 200554 2549-2556. (doi:10.2337/diabetes.54.9.2549)

31 Lang KS, Recher M, Junt T, Navarini AA, Harris NL, Freigang S, Odermatt B, Conrad C, Ittner LM, Bauer S et al. Toll-like receptor engagement converts T-cell autoreactivity into overt autoimmune disease. Nature Medicine 200511 138-145. (doi:10.1038/nm1176)

32 Rasschaert J, Ladrière L, Urbain M, Dogusan Z, Katabua B, Sato S, Akira S, Gysemans C, Mathieu C \& Eizirik DL. Toll-like receptor 3 and STAT-1 contribute to double-stranded RNA + interferon- $\gamma$-induced apoptosis in primary pancreatic $\beta$-cells. Journal of Biological Chemistry 2005280 33984-33991. (doi:10.1074/jbc.M502213200)

33 Dogusan Z, Garcia M, Flamez D, Alexopoulou L, Goldman M, Gysemans C, Mathieu C, Libert C, Eizirik DL \& Rasschaert J. Doublestranded RNA induces pancreatic $\beta$-cell apoptosis by activation of the Toll-like receptor 3 and interferon regulatory factor 3 pathways. Diabetes 200857 1236-1245. (doi:10.2337/db07-0844)

34 Ylipaasto P, Kutlu B, Rasilainen S, Rasschaert J, Salmela K, Teerijoki H, Korsgren O, Lahesmaa R, Hovi T, Eizirik DL et al. Global profiling of coxsackievirus- and cytokine-induced gene expression in human pancreatic islets. Diabetologia 200548 1510-1522. (doi:10.1007/ s00125-005-1839-7)

35 Hultcrantz M, Huhn MH, Wolf M, Olsson A, Jacobson S, Williams BR, Korsgren $\mathrm{O} \&$ Flodstrom-Tullberg M. Interferons induce an antiviral state in human pancreatic islet cells. Virology 2007 367 92-101. (doi:10.1016/j.virol.2007.05.010)

36 Sobel DO, Newsome J, Ewel CH, Bellanti JA, Abbassi V, Creswell K \& Blair O. Poly I:C induces development of diabetes mellitus in BB rat. Diabetes 199241 515-520. (doi:10.2337/diab.41.4.515) 
37 Moriyama H, Wen L, Abiru N, Liu E, Yu L, Miao D, Gianani R, Wong FS \& Eisenbarth GS. Induction and acceleration of insulitis/diabetes in mice with a viral mimic (polyinosinic-polycytidylic acid) and an insulin selfpeptide. PNAS 200299 5539-5544. (doi:10.1073/pnas.082120099)

38 Wen L, Peng J, Li Z \& Wong FS. The effect of innate immunity on autoimmune diabetes and the expression of Toll-like receptors on pancreatic islets. Journal of Immunology 2004172 3173-3180. (doi:0022-1767/04/S02.00)

39 McCartney SA, Vermi W, Lonardi S, Rossini C, Otero K, Calderon B, Gilfillan S, Diamond MS, Unanue ER \& Colonna M. RNA sensorinduced type I IFN prevents diabetes caused by a $\beta$ cell-tropic virus in mice. Journal of Clinical Investigation 2011121 1497-1507. (doi:10.1172/JCI44005)

40 Alkanani AK, Rewers M, Dong F, Waugh K, Gottlieb PA \& Zipris D. Dysregulated Toll-like receptor-induced interleukin- $1 \beta$ and interleukin- 6 responses in subjects at risk for the development of type 1 diabetes. Diabetes 201261 2525-2533. (doi:10.2337/db12-0099)

41 Eleftherohorinou H, Wright V, Hoggart C, Hartikainen AL, Jarvelin MR, Balding D, Coin L \& Levin M. Pathway analysis of GWAS provides new insights into genetic susceptibility to 3 inflammatory diseases. PLOS ONE 20094 e8068. (doi:10.1371/journal.pone.0008068)
42 Howson JM, Cooper JD, Smyth DJ, Walker NM, Stevens H, She JX, Eisenbarth GS, Rewers M, Todd JA, Akolkar B et al. Evidence of genegene interaction and age-at-diagnosis effects in type 1 diabetes. Diabetes 201261 3012-3017. (doi:10.2337/db11-1694)

43 Todd JA, Walker NM, Cooper JD, Smyth DJ, Downes K, Plagnol V, Bailey R, Nejentsev S, Field SF, Payne F et al. Robust associations of four new chromosome regions from genome-wide analyses of type 1 diabetes. Nature Genetics 200739 857-864. (doi:10.1038/ng2068)

44 Barrett JC, Clayton DG, Concannon P, Akolkar B, Cooper JD, Erlich HA, Julier C, Morahan G, Nerup J, Nierras C et al. Genome-wide association study and meta-analysis find that over 40 loci affect risk of type 1 diabetes. Nature Genetics 200941 703-707. (doi:10.1038/ ng.381)

45 Choe J, Kelker MS \& Wilson IA. Crystal structure of human Toll-like receptor 3 (TLR3) ectodomain. Science 2005309 581-585. (doi:10.1126/ science.1115253)

46 Gorbea C, Makar KA, Pauschinger M, Pratt G, Bersola JL, Varela J, David RM, Banks L, Huang CH, Li H et al. A role for Toll-like receptor 3 variants in host susceptibility to enteroviral myocarditis and dilated cardiomyopathy. Journal of Biological Chemistry 2010285 23208-23223. (doi:10.1074/jbc.M109.047464)

Received 26 November 2013

Revised version received 6 January 2014

Accepted 9 January 2014 